\title{
Determinants of Decarbonisation in the Transformation of the Energy Sector: The Case of Poland
}

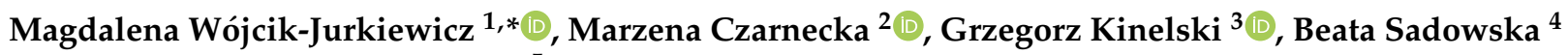 \\ and Katarzyna Bilińska-Reformat ${ }^{5}$
}

1 Department of Accounting, Institute of Management, College of Management Sciences and Quality, Cracow University of Economics, 31-510 Kraków, Poland

2 Department of Law and Insurance, College of Finance, University of Economics Katowice, 40-287 Katowice, Poland; marzena.czarnecka@ue.katowice.pl

3 Department of Management, WSB University, 41-300 Dabrowa Górnicza, Poland; grzegorz.kinelski@gmail.com

4 Department of Accounting, Faculty of Economics and Management, University of Szczecin, 70-453 Szczecin, Poland; beata.sadowska@usz.edu.pl

5 Department of Marketing Management and Tourism, College of Management, University of Economics Katowice, 40-287 Katowice, Poland; katarzyna.bilinska-reformat@ue.katowice.pl

* Correspondence: magdalena.wojcik-jurkiewicz@uek.krakow.pl

check for updates

Citation: Wójcik-Jurkiewicz, M.; Czarnecka, M.; Kinelski, G.;

Sadowska, B.; Bilińska-Reformat, K. Determinants of Decarbonisation in the Transformation of the Energy Sector: The Case of Poland. Energies 2021, 14, 1217. https://doi.org/ 10.3390/en14051217

Academic Editors: Kostas Kounetas and Nicholas Apergis

Received: 31 December 2020

Accepted: 22 February 2021

Published: 24 February 2021

Publisher's Note: MDPI stays neutral with regard to jurisdictional claims in published maps and institutional affiliations.

Copyright: (c) 2021 by the authors. Licensee MDPI, Basel, Switzerland. This article is an open access article distributed under the terms and conditions of the Creative Commons Attribution (CC BY) license (https:/ / creativecommons.org/licenses/by/ $4.0 /)$.

\begin{abstract}
This paper aims to identify the determinants of the decarbonisation processes in Poland within the scope of energy transformation. The purpose of the study is to identify how the public perceives decarbonisation determinants in order to develop a sustainable energy strategy for Poland. The transition of the energy market to low-carbon technology is a policy challenge. Governments must implement policies that are environmentally friendly, cost-effective, but, most of all, socially acceptable. Social acceptance risk plays a significant role in Poland, influencing the decarbonisation process. In Poland's case, the coal share is decreasing, but it is still the most important fuel for electricity production. This process of decarbonisation is a fundamental influence on the transformation of the energy sector in Poland. The social perception of solutions that can be applied was examined. The Polish natural environment is poisoned. Poles suffer from diseases related to the burning of coal for energy production. Societal awareness, how people perceive the government's actions, and what they expect in this regard is crucial.
\end{abstract}

Keywords: decarbonisation; energy transition; low-carbon technology; energy policy; climate change

\section{Introduction}

Poland is not only using coal for much of its energy mix. Poland is also a significant producer of coal. The decarbonisation of the energy sector is therefore, closely linked to the linear reduction of the coal sector. This is also connected to the reduction of employment in the Polish coal mining industry. Our case study for Poland shows that in the past, about fifty per cent of all mining workers, who have left their job, have not moved to other industries and remained unemployed. This phenomenon should be explained, inter alia, by the fact that the level of education of miners is lower than the average on the labour market. This can also be explained by lower wages in sectors other than the mining sector.

Poland faces unique challenges in its energy transition due to the extreme dependence on coal. Nevertheless, many countries are already going through or will undertake the transition to a low-carbon economy [1] The traditional model for development and industrialisation is resource- and energy-intensive, with economic growth accompanied by increasing carbon dioxide $\left(\mathrm{CO}_{2}\right)$ emissions [2,3]. Keeping the average global temperature rise below $2{ }^{\circ} \mathrm{C}$ will require a drastic reduction in global net greenhouse gas emissions and, ultimately, zero emissions [4]. It is now considered possible to decarbonise economic growth and to achieve deep reductions in greenhouse gas emissions while increasing 
economic activity and prosperity [5]. Decarbonisation is based on better energy efficiency and the supply of zero-emission clean electricity instead of fossil fuel-derived electricity, where possible [6-8]. The necessary technologies already exist and are becoming increasingly available. There could also be considerable additional benefits, such as cleaner local environments and economic modernization [9-11]. However, making the transition to lowcarbon technology is a policy challenge. Governments must implement environmentally friendly, cost-effective, and socially acceptable policies [12,13]. Social acceptance risk plays a significant role in Poland, influencing the decarbonisation process. Social acceptance is essential: we need to ask whether citizens' social acceptability is the same as economic viability, and if it is economically relevant [14-16].

Decarbonization without excluding energy security in the SEE region is a priority of EU foreign and environmental policy. Two strategic and complementary goals that both the EU and SEE countries are pursuing are political factors related to the supply of Russian natural gas and the transition from coal to gas. However, these goals have always undermined the composition of energy mixes, the degree of integration of energy supplies with the EU's energy hubs, the degree of integration of energy markets in the region, and the diversification of existing gas supplies since the late 1990s [17].

Overall, there is a shift away from coal and ultimately also from gas and oil. Decarbonisation fosters further economic growth and more sustainable forms of economic growth and energy transformation in all domestic studies [18].

Decarbonisation will mean the collapse of significant subsets of existing industries, especially fossil. They will be replaced by new initiatives that will bring about new investments, profitable opportunities, and jobs. It could create fear of energy transition. Issues could become sharply defined in regional and timescale terms, leading to severe social difficulties $[19,20]$. It is therefore necessary to establish how these processes have been perceived socially.

In recent years, numerous programmes have emerged to reduce the economic inequality between countries and overcome the ecological crisis. Wealthy nations must lead by example by drastically reducing fossil fuel consumption, adopting more sober patterns of natural resources consumption, and helping low-income countries to reduce poverty and improve their environmental technologies [21]. However, each of these moves have been vigorously opposed by leading multinational corporations, which have tremendous economic and political power over governments and international financial institutions. A substantial civil action is required to reduce fossil fuel use and switch to renewable energy while reducing inequalities between and within nations and redefining the global economic development model. Our generation's critical question is whether the mass social movement advocating decarbonisation will be the correct one.

The remainder of this paper is organized as follows. The methodology is introduced in Section 2 and a relevant literature review is provided. Section 3 presents the justification. Section 4 includes the results. The discussion and conclusions are presented in Section 5, which ends the paper.

\section{Methods}

The purpose of this study is to identify the determinants of the decarbonisation processes in Poland. This study also shows the directions enabling the diffusion of knowledge regarding decarbonisation to develop a sustainable energy strategy for Poland.

This study applies methodological triangulation, which consists of combining qualitative and quantitative methods in many ways, according to a new paradigm in management sciences that advocates combining several approaches and methods to manage open epistemological and methodological attitudes. The choice of research methods and techniques was the result of conceptualisation and operationalisation processes. The questionnaire method was used in the study.

The literature review intends to assess current knowledge concerning the role of information, the information needs of enterprises and their stakeholders, the importance 
of an integrated information system of a business unit, and determining the place of management accounting in this system.

The survey was conducted online and consisted of 12 research questions. An online survey provides many possibilities to present problems, collect answers, and offer respondents flexibility and convenience. In designing the research tool, we initially adopted the previous literature's assumptions, according to which decarbonisation processes are focused on reducing $\mathrm{CO}_{2}$ emissions. The design of the research tool was based on standardised and verified tools. The research was based on a survey by the Tyndall Centre for Climate Research (Critical Issues in Decarbonising Transport Final Report of the Theme 2 project T2.22, Ian Skinner1, Malcolm Fergusson and Katharina Kröger2, Institute for European Environmental Policy (IEEP); Charlotte Kelly and Abigail Bristow, Institute for Transport Studies (ITS) University of Leeds, 2003). The survey asked two questions, with responses based on the Likert scale. The questions concern fundamental issues with the determinants supporting decarbonisation processes in Poland and the model of decarbonisation (centralism vs. localism) in the scope of the energy transition. The survey included two open-ended questions about the most effective legal solutions to support Poland's decarbonisation processes and the essential determinants supporting them.

The research was conducted between December 2019 and April 2020. The survey included 444 respondents who filled in the questionnaire, of which $46 \%$ (205) were men and $54 \%$ (239) were women. The following assumptions were made for statistical research. Confidence level shows how sure the researchers can be of the obtained results, the $\alpha=0.95$ indicates a level of certainty of $95 \%$. Another indicator is the size of the fraction. In this case, when we estimate that a given characteristic occurs in $60 \%$ of the population, we assume 0.6. If we do not know this value, we take the value of this indicator as 0.5 . Another indicator is the maximum error. It indicates to us what level of correction we should assume. For example, if we create a $0.03 \%$ or $3 \%$ error and conduct an election poll among supporters of political parties. When analyzing the results, we observe that a given party achieved a score of $20 \%$, then with our assumption of an error of $3 \%$, real support can vary by $3 \%$ up or down.

It brings the minimum sample size to 384 , for whole population 38 million people in Poland. The primary coarse static division resulting from parity has been retained. The research group's additional structures are in line with the statistics of social, age and geolocation groups of the most interested. It mainly affects the inhabitants of affected regions, such as Silesia.

This brings the minimum sample size to 384 , for the whole population of 38 million people in Poland. The primary coarse static division resulting from parity has been retained. The research group's additional structures are in line with the statistics of social, age, and geolocation groups of the most interested. It mainly affects the inhabitants of affected regions, such as Silesia.

The individual activities indicated in the survey are assigned one of the following grades:

1. no impact;

2. very little/negligible impact;

3. neutral;

4. visible impact; and

5. significant impact.

Another question, "What do you think the EU should introduce in terms of solutions and regulations regarding decarbonisation?" concerns solutions the EU should introduce in decarbonisation. It was an open-ended question in that respondents could give a free, subjective answer, or several answers. When asking open-ended questions, we intended to obtain as many attitudes and opinions as possible to analyse the studied phenomenon, including decarbonisation.

The research was exploratory, conducted to determine the nature of the problem, and was not intended to provide conclusive evidence but to understand the issue better [22]. 
The sampling was focused on respondents dealing with the problem of decarbonisation. Table 1 presents the structure of the sample.

Table 1. Sample characteristics.

\begin{tabular}{ll}
\hline Age & No \\
\hline 1961-1981 (Generation X) & 122 \\
1982-2000 (Generation Y) & 301 \\
2001-Present (Generation Z) & 8 \\
1943-1960 (Baby boomers (BB)) & 13 \\
Place of residence & No \\
City & 317 \\
Village & 127 \\
Sex & No \\
Male & 205 \\
Female & 239 \\
\hline
\end{tabular}

Source: Own research.

Among the respondents, most people were aged up to 25, while one-quarter were aged 26-35. The smallest group was comprised of people aged over 35 . Such an age distribution can be explained by the fact that the direct survey was performed via mail. As for the respondents' education, almost half of them had higher vocational education and $20 \%$ had MBAs.

According to Poovey (p. 84), "there are limits to what the rationalised knowledge epitomised by statistics can do." Qualitative research can draw strong attention to detail, covering both verbal and nonverbal behaviour and uncovering nuances [22] (pp. 454-462).

\section{Justification}

As we mentioned, this study aims to identify the determinants of decarbonization processes in Poland $[23,24]$. We believe that our research contributes to the literature because, even though decarbonization has been discussed in both EU and international literature, there is no reference to knowledge-diffusion processes as the causative factors for those changes.

Climate change and environmental degradation pose a threat to Europe and the rest of the world. To meet these challenges, Europe needs a new growth strategy to transform the energy market into a modern, resource-efficient, and competitive economy with the following characteristics $[25,26]$ :

- $\quad$ zero net greenhouse gas emissions by 2050;

- $\quad$ economic growth decoupled from resource consumption; and

- $\quad$ no person or region left behind.

Successful implementation of the EU decarbonisation action plan requires the consideration of technologies, policy concepts, and social aspects, which are closely intertwined. For example, technological solutions are needed for emissions at an acceptable cost from a global perspective. The development of an appropriate policy is necessary to transfer climate policy benefits to the EU macro level and, further, to the local government or even to the consumer level. Markets can adapt by postponing investment until conditions are favourable for decarbonisation. It seems necessary to keep low-carbon subsidies for longer than expected $[27,28]$. In this sense, the EU hopes that its example will encourage other regions of the world to follow suit. Such a strong drive could develop new industries based on cutting-edge clean and low-carbon technologies, strengthen the EU, and help overcome the economic crisis by initiating the necessary changes for a more sustainable policy. To this end, the EU has set itself the overarching goal of reducing the greenhouse effect by 2050 [29].

In the article, the authors analysed various determinants influencing the decarbonisation of electricity by 2050 from a social point of view. The first determinant to be examined is mining. More than 25 countries, especially in Asia, have revised their fossil fuel subsi- 
dies in recent years. However, according to the International Monetary Fund, the cost of these subsidies, including environmental and health damage, amounts to approximately US\$5.3 trillion annually. These subsidies distort prices to the detriment of decarbonisation. They harm the environment, curb the spread of greener technologies, and burden national budgets [30,31].

Contrary to popular belief, subsidising fossil fuels is not an effective way to increase competitiveness and help the poor. Instead, according to the World Bank, these subsidies benefit the rich. However, despite the abolition of subsidies, it tends to promote equality, while at the same time increasing the prices of energy and other goods, lowering the purchasing power of lower-income households, and leading to an industrialisation-based energy slowdown. Therefore, the savings obtained by abolishing subsidies must be used to compensate for the loss of income among the poor and strengthen the network's social security [32].

The second determinant is subsidies for local governments (e.g., decommissioning of furnaces), as investments in renewable energy sources are supported by the subsidy system. For this reason, renewable energy is still more expensive than conventional energy. For investment projects in renewable energy sources to provide investors with an appropriate return on the invested capital, the subsidy system must be stable. When the subsidy system is destabilised, investment risk and credit risk increase immeasurably, which may significantly slow down planned investments in the renewable energy system. The system of financial support renewable energy system (RES) should be stabilised to develop green energy.

Poland will follow in the footsteps of other EU countries that subsidise electricity production from wind, solar, biomass, or biogas. In the EU, renewable energy sources are developing. Countries are guaranteed a fixed price for RES (the feed-in tariff system), or energy distributors are obliged to buy securities from producers of green energy (socalled green certificates); thus, compliance is a legal requirement. In both cases, consumers ultimately pay for RES support.

Proconsumer solar photovoltaic development programmes are a crucial element of decarbonisation, related to government policy and bottom-up initiatives. When energy consumers see that they can obtain energy from renewable sources practically for free, the post-renewable energy system stage is likely to continue indefinitely. In this case, the stability of both regulations and planning is necessary. Of course, the pace of abandoning fuel will differ in different sectors. It is one thing to, for example, stop using coal in households; it is quite another to replace a heating system in an energy enterprise [31].

The next determinant, the market capacity, does not directly affect the development of renewable sources. The level of renewable energy system ambition depends on political decisions. However, indirectly, the capacity market will create new possibilities for integrating variable sources in the system. There is a chance that energy storage will develop within the capacity market. Warehouses most often supplement wind installations and store energy when it blows, and the market demand is small. In periods of high market demand for energy, batteries can be discharged and the national energy system can be powered for $4 \mathrm{~h}$. The wind energy storage facility meets the availability requirements as well as conventional installations.

One of the most critical determinants influencing decarbonisation is opening up the EU energy market. In 2018 EU institutions and Member States' governments decided to impose stricter targets on renewable energy regulations. In November 2018, the Commission presented its updated vision for building a low-carbon economy by 2050: "A Clean Planet for all-A European strategic long-term vision for a prosperous, modern, competitive and climate neutral economy." The document provides a detailed analysis of the changes needed to achieve the envisaged emission reductions. This vision is more ambitious than the EC's 2011 "Roadmap for moving to a competitive low-carbon economy in 2050": it is not limited to reducing emissions by $80 \%$, outlines the possibility of achieving climate neutrality by 2050. Europe's planned transition to a net-zero economy by 2050 implies 
the need to change national policies. It is also Poland. The country should formulate a long-term strategy for a low carbon economy including not only electricity generation but also other sectors. [31].

Another element influencing decarbonisation is energy efficiency; one of the drivers of this development is annual electricity production, which increased from $6300 \mathrm{Mt}$ to 11,700 Mt in 1990-2013 [9] (pp. 56-63). Policymakers have introduced restrictions and trading systems (e.g., the European Emissions Trading System) or initiated support schemes for renewable energy (e.g., tariffs).

When it comes to renewable energy sources, irregular supply is a challenge for decarbonisation [32,33]. Complementary technologies that can respond to rapid changes in the supply of renewable energy and provide the necessary flexibility on the supply side include coal or gas plants, biomass plants (which are rarely suitably located), batteries and gas (which are still too expensive), and short-term demand response.

Thus, there is increasing emphasis on long-term demand response measures, such as energy efficiency, which reduces the overall electricity demand that needs to be met. For example, the International Energy Agency calculates that improving energy efficiency reduced carbon emissions by 12.5\% between 2000 and 2016 [34] (p. 27).

This study addresses the scientific problem of decarbonisation and changes in diffusion in the practice of that process and attempts to find a solution to it. Many determinants condition the decarbonisation of national economies. It is difficult to assess what kind of determinants play a crucial role in decarbonisation processes in many cases. Schmidt and Weight further observe that, within energy studies, interdisciplinary works are rare: "despite the pre-dominantly socio-economic nature of energy demand, such inter-disciplinary viewpoints-albeit on the rise-are still the minority within energy-related research" [22] (pp. 206-219). That is why the authors have tried to carry out such studies.

The traditional energy market is currently in transition towards a more flexible energy system in where energy production is decentralized and based on renewable energy sources, technical platforms are smart and multiple actors can participate in the energy process. The role of end-user is evolving from a consumer to a prosumer, i.e., a producer and consumer of energy. The energy consumers and prosumers are expected to become significant players in the future energy ecosystem, enabling a new type of innovation and value creation opportunities for a variety of actors. It is important to investigate how individuals recognize determinants of decarbonization. The findings highlight how determinants of decarbonization can play an active role in the transformation of the traditional energy market.

In the literature on decarbonisation processes, no broad theoretical explanations indicate the crucial determinants supporting such operations.

\section{Results}

The research yields answers to the following research question: Which of the following do you think has the most impact on decarbonisation?

1. Subsidies for mining.

2. Subsidies for local governments (e.g., the decommissioning of furnaces).

3. Prosumer solar photovoltaics development programmes.

4. Capacity market.

5. Opening up the EU energy market.

The answers to the questions are presented in Figure 1. 


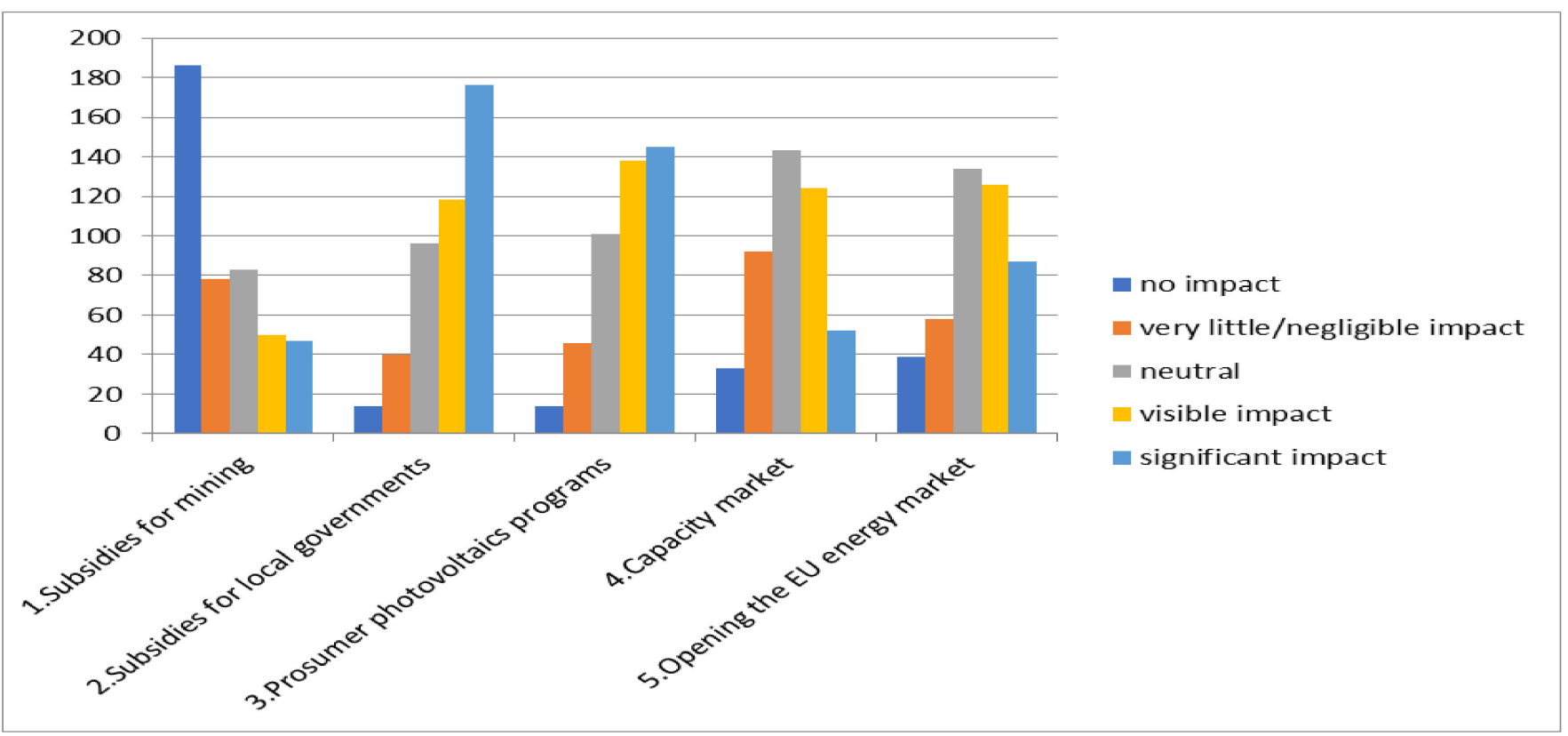

Figure 1. Respondents' opinions on the activities determining decarbonisation processes. Source: Own research based on the results of an online survey, $n=444$.

Of the respondents, $42 \%$ stated that mining subsidies had no impact on the decarbonisation process; $19 \%$ believed that mining subsidies were a factor increasingly influencing the decarbonisation process, and $11 \%$ thought that the mining subsidy policy had a significant impact on decarbonisation.

The opposite situation was observed with respondents' responses to the question "Which of the following measures has the greatest impact on decarbonisation, in your opinion?" Forty percent of participants stated that subsidies for local governments (e.g., decommissioning of furnaces) significantly impacted decarbonisation, while $22 \%$ believed that such subsidies increasingly affected measures to reduce $\mathrm{CO}_{2}$ emissions. According to $3 \%$ of respondents, subsidies for local governments had no impact on the decarbonisation process.

For $64 \%$ of respondents, the development programmes for prosumer solar photovoltaics had a significant or reasonably large impact on eliminating $\mathrm{CO}_{2}$ emissions due to their harmfulness to the environment. Only 3\% of respondents believed that these programmes did not affect decarbonisation (Figure 1).

Another topic in the survey concerned the power market, which constitutes regulatory solution stabilizing the electricity supply to households and industries as part of a longterm plan. Therefore, it is a guarantee of uninterrupted electricity supply to all electricity consumers. The capacity market in Poland was introduced in 2017 and is expected to operate until 2046. The security of covering the forecast demand of consumers for power in a given year is contracted several years in advance; therefore, respondents were asked whether, in their opinion, the capacity market influenced decarbonisation.

The responses of the survey participants were quite similar to each other and were as follows (Figure 1):

- $\quad$ no impact $(7 \%)$;

- $\quad$ very little/negligible impact $(21 \%)$;

- hard to tell (32\%);

- $\quad$ visible impact $(28 \%)$; and

- $\quad$ significant impact on decarbonisation (12\%).

The last question in the survey concerned the EU free energy market. The participants answered this question similarly to the previous ones. Fifty-eight percent believed that the EU free energy market would increasingly impact the elimination of $\mathrm{CO}_{2}$ emissions, $20 \%$ 
considered that it had a significant impact on decarbonisation, and only $9 \%$ believed that it would make no difference.

When respondents answered the second question, of which of the following activities should be transferred from the central level to the local level, nearly $86 \%$ stated that subsidies for local governments and photovoltaics development programmes significantly impact decarbonisation (Figure 2).

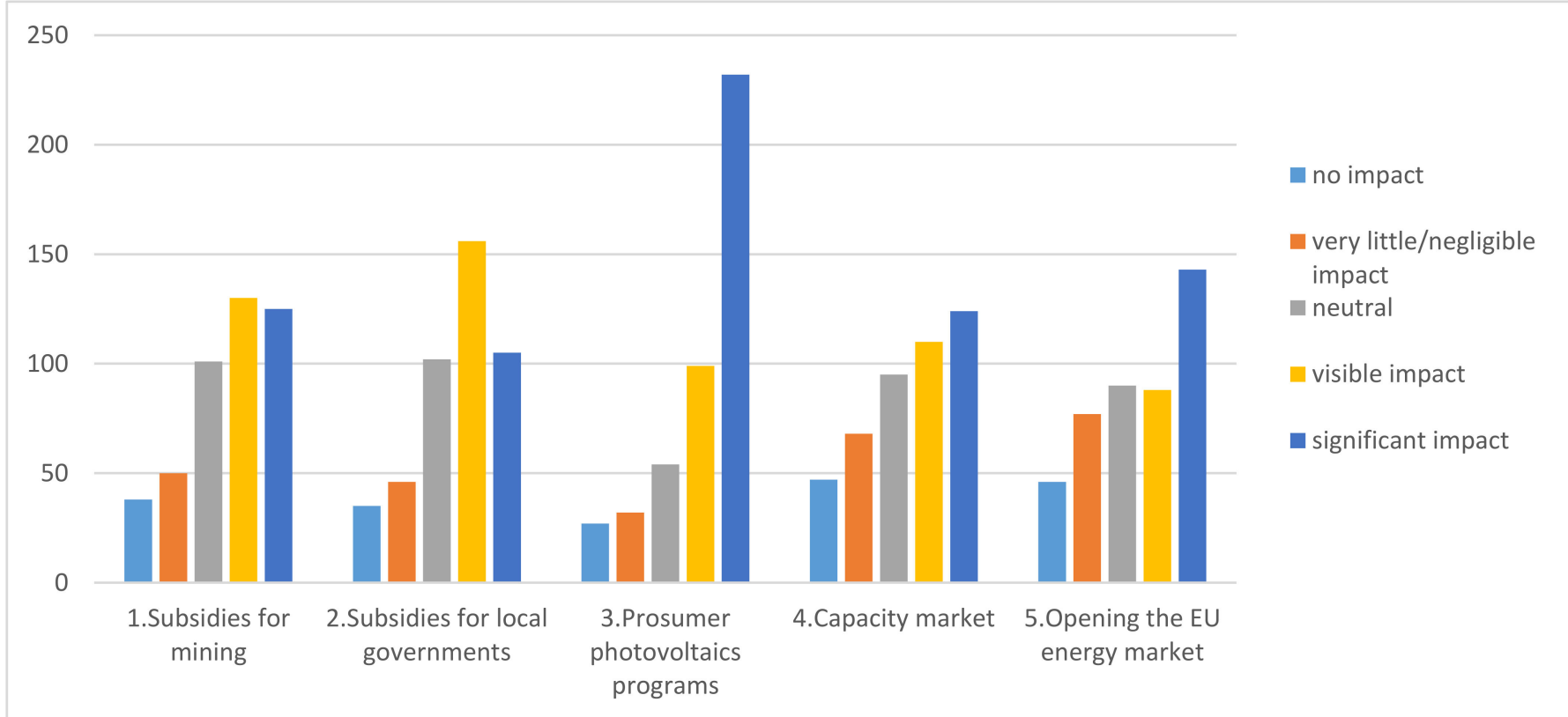

Figure 2. Respondents' opinions on the activities determining decarbonisation processes (Question 2: (Which of the following activities should be transferred from central to local regulation?). Source: Own research based on the results of an online survey, $n=444$.

The responses of the survey participants were quite similar to each other and were as follows (Figure 2):

- $\quad$ no impact (14\%);

- $\quad$ very little/negligible impact $(15 \%)$;

- $\quad$ hard to tell (41\%);

- $\quad$ visible impact $(7 \%)$; and

- $\quad$ significant impact on decarbonisation (23\%).

According to the answers received in the study, 59 respondents believe that activities related to the decarbonisation of the economy, including granting subsidies to residents/recipients (e.g., for the liquidation of the back) should not be transferred from the central to the local level. Fifty-four respondents indicated that it is difficult for them to assess this phenomenon, and 99 people participating in the study did not have a firm opinion on the subject. In response to this question, the dominant opinion (232 respondents) was that activities refering to the decarbonisation of the economy, i.e., the granting of subsidies to residents/recipients (e.g., for the liquidation of furnaces) should be transferred from the central level to the local level.

Another area of scientific research on the transfer of activities related to the economy's decarbonisation from the central to the local level was prosumer photovoltaic development programmes. Eighty-one respondents answered that, in their opinion, these programmes should not be transferred from the central to the local level; 102 people taking part in the survey found it difficult to assess this phenomenon. It can be assumed that these people do not have adequate knowledge of the subject. As many as 105 people did not have a precise opinion, and 156 respondents believed that activities related to the decarbonisation of the 
economy, including the management of programmes for the development of prosumer photovoltaics, should be transferred from the central to the local level.

According to $19.81 \%$ of respondents, activities related to the decarbonisation of the economy, including energy compensation, energy storage, and production by day and night, should not be transferred from the central to the local level $(8.55 \%$ of respondents had a strong opinion in this respect). According to the data presented in Figure 2, it was difficult for the respondents to assess this phenomenon as they did not have a firm opinion on the subject $(27.74 \%)$. As many as $57.42 \%$ of respondents thought that such activities related to the decarbonisation of the economy as energy compensation, energy storage, daytime energy production, and night-time consumption should be transferred from the central level to the premises (28.15\% of respondents had a strong opinion in this respect).

The data from Table 2 are presented in Figure 3. They are the means of all responses obtained in the studies. They show that subsidies for mining are the least important factor for all generations. They have no or a minimal impact on decarbonisation. This is illustrated by the lowest average response value for all ages (especially the youngest, Generation Z) regarding the opening of the EU energy market. Older generations pay attention to local subsidies and the development of photovoltaics. However, Generation $Z$ was the least numerous group. Therefore, it can be assumed that the responses obtained from Generations $X$ and $Y$ are the most representative (Table 3).

Table 2. Respondents' opinions on the average importance of the impact on decarbonisation.

\begin{tabular}{cccccc}
\hline & \multicolumn{5}{c}{ Average of Importance of Impact on Decarbonisation } \\
\hline Age & A & B & C & D & E \\
\hline 1943-1960 (Baby boomers (BB)) & 2.15 & 3.85 & 3.92 & 2.69 & 3.23 \\
1961-1981 (Generation X) & 2.08 & 3.84 & 3.93 & 3.08 & 3.44 \\
1982-2000 (Generation Y) & 2.40 & 3.96 & 3.75 & 3.20 & 3.33 \\
2001-Present (Generation Z) & 2.75 & 3125 & 3.5 & 3.5 & 4.0 \\
Total & 2.31 & 3.91 & 3.80 & 3.16 & 3.37 \\
\hline
\end{tabular}

Source: Own research. A-Subsidies for mining; B-Subsidies for local governments; C-Prosumers' photovoltaics development programme; D-Capacity market; E-The opening-up of the EU energy market.

\section{Advanced Statistical Analysis}

The median is calculated, assuming what follows:

Assumption:

$$
x_{1} \leq x_{2} \leq \ldots \leq x_{n}
$$

DI:

$$
m_{e}=\left\{\begin{array}{c}
x_{(n+1) / 2} \\
\frac{1}{2}\left(x_{n / 2}+x_{n / 2+1}\right)
\end{array}\right.
$$

for n-odd; for n-even.

SzR:

$$
m_{e}=\overline{x_{m}}+\frac{d}{n_{m}}\left(\frac{n-n_{m}}{2}-\sum_{j=1}^{m-1} n_{j}\right)
$$

The variances from the sample were calculated $\left(s^{2}\right.$-sample variance): DI:

$$
s^{2}=\frac{1}{n} \sum_{i=1}^{k}\left(x_{i}-\bar{x}\right)^{2}
$$

SzR:

$$
s^{2}=\frac{1}{n} \sum_{j=1}^{k} n_{j}\left(\overline{x_{j}}-\bar{x}\right)^{2}
$$

Thus, $s$ is the standard deviation. 


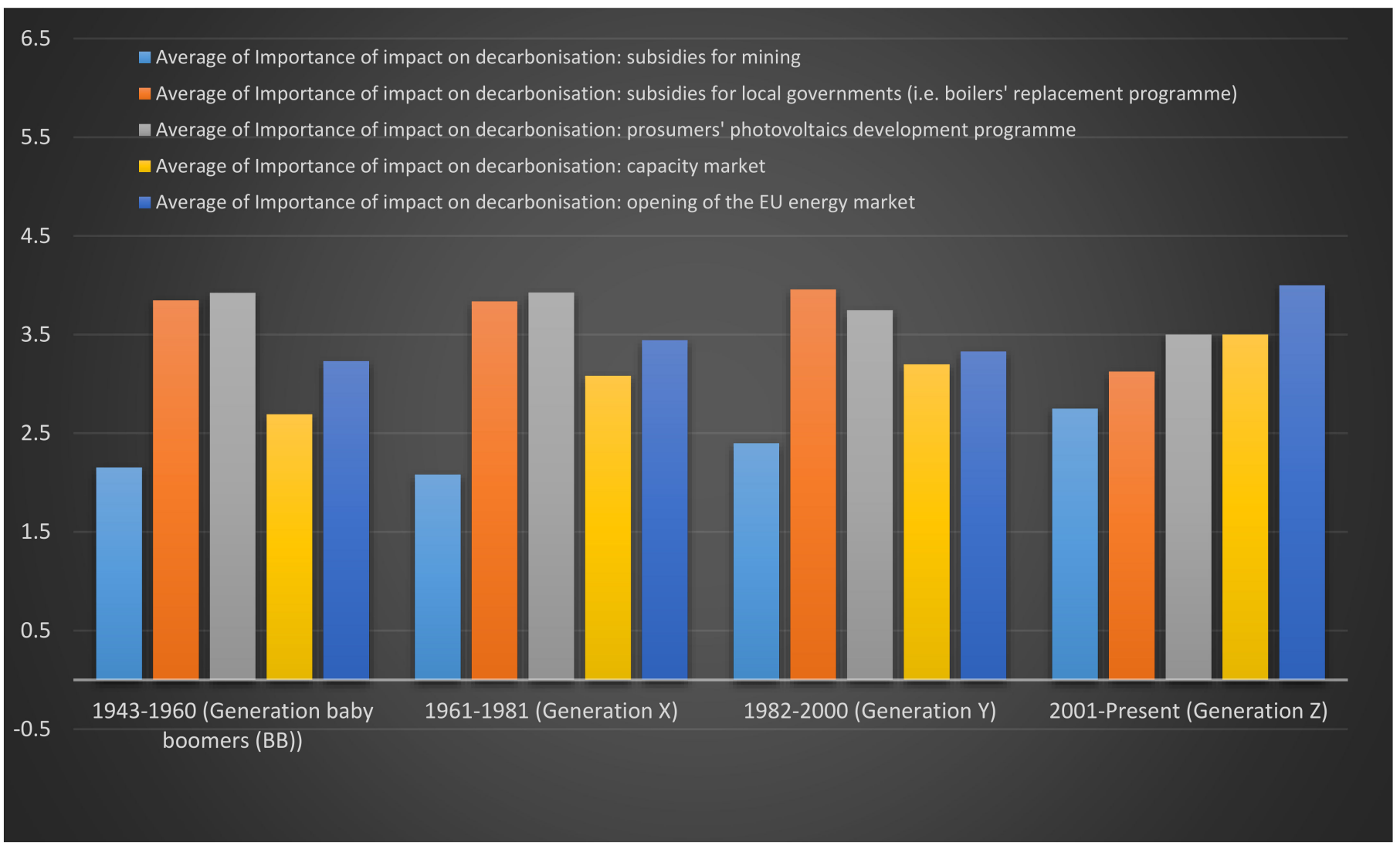

Figure 3. Average importance of impact on decarbonisation. Source: Own research based on the results of an online survey, $n=444$.

Table 3. Count of the importance of impact on decarbonisation.

\begin{tabular}{|c|c|c|c|c|c|c|c|}
\hline \multicolumn{8}{|c|}{ Importance of Impact on Decarbonisation: Subsidies for Mining } \\
\hline \multirow{2}{*}{ Age } & \multicolumn{2}{|c|}{ City } & \multirow{2}{*}{ City Total } & \multicolumn{2}{|c|}{ Village } & \multirow{2}{*}{ Village Total } & \multirow[t]{2}{*}{ Total } \\
\hline & Female & Male & & Female & Male & & \\
\hline 1943-1960 (Baby boomers (BB)) & 5 & 4 & 9 & 1 & 3 & 4 & 13 \\
\hline 1 & 2 & 3 & 5 & & 1 & 1 & 6 \\
\hline 2 & 1 & & 1 & 1 & 1 & 2 & 3 \\
\hline 3 & 1 & & 1 & & & & 1 \\
\hline 4 & 1 & & 1 & & 1 & 1 & 2 \\
\hline 5 & & 1 & 1 & & & & 1 \\
\hline 1961-1981 (Generation X) & 32 & 64 & 96 & 13 & 13 & 26 & 122 \\
\hline 1 & 16 & 38 & 54 & 3 & 10 & 13 & 67 \\
\hline 2 & 4 & 10 & 14 & 2 & 2 & 4 & 18 \\
\hline 3 & 4 & 7 & 11 & 3 & & 3 & 14 \\
\hline 4 & 3 & 1 & 4 & 1 & 1 & 2 & 6 \\
\hline 5 & 5 & 8 & 13 & 4 & & 4 & 17 \\
\hline 1982-2000 (Generation Y) & 111 & 94 & 205 & 71 & 25 & 96 & 301 \\
\hline 1 & 39 & 41 & 80 & 18 & 12 & 30 & 110 \\
\hline 2 & 18 & 21 & 39 & 14 & 4 & 18 & 57 \\
\hline 3 & 24 & 16 & 40 & 22 & 4 & 26 & 66 \\
\hline 4 & 18 & 7 & 25 & 13 & 2 & 15 & 40 \\
\hline 5 & 12 & 9 & 21 & 4 & 3 & 7 & 28 \\
\hline od 2001-Present (Generation Z) & 5 & 2 & 7 & 1 & & 1 & 8 \\
\hline 1 & 2 & 1 & 3 & & & & 3 \\
\hline 3 & 1 & 1 & 2 & & & & 2 \\
\hline 4 & 2 & & 2 & & & & 2 \\
\hline 5 & & & & 1 & & 1 & 1 \\
\hline
\end{tabular}


Standard deviation is one of the measures of dispersion (variability, dispersion) intended for testing the degree of variation in the value of a variable. Generally, the standard deviation reflects how much the variable's values in the studied population deviate from the arithmetic mean of the studied variable's value. High values of standard deviation indicate that the variable's values are forcefully dispersed around the mean (considerable differentiation), while low values indicate small dispersion (low differentiation).

The standard deviation is strongly related to the arithmetic mean. We have already noted that the arithmetic mean is useful for examining a population with a low degree of differentiation of the variable feature. At the same time, its disadvantages include distorting the result of the mean by adding extreme values. Groups that are not characterised by homogeneity are often a focus of study; in our case, the arithmetic mean has a low cognitive value. So, the standard deviation comes to our aid.

We can also calculate the standard deviation as follows:

$$
s=\sqrt{\frac{\left(x_{1}-\bar{x}\right)^{2}+\left(x_{2}-\bar{x}\right)^{2}+\ldots+\left(x_{n}-\bar{x}\right)^{2}}{n-1}}
$$

where $s$ symbolises the standard deviation and $n-1$ is the number of samples minus 1 .

Figure 4 presents the means obtained from the answers to the impact of decarbonisation and standard deviations. They clearly show that all standard deviations are in the range from 1.5 to 2.6. The respondents' most unambiguous answers from Generation $\mathrm{Z}$, however, cannot be taken into account due to their small size. Yet, also for baby boomers, very high and singular recognition (with a low standard deviation) was given to the proconsumer photovoltaic development programmes.

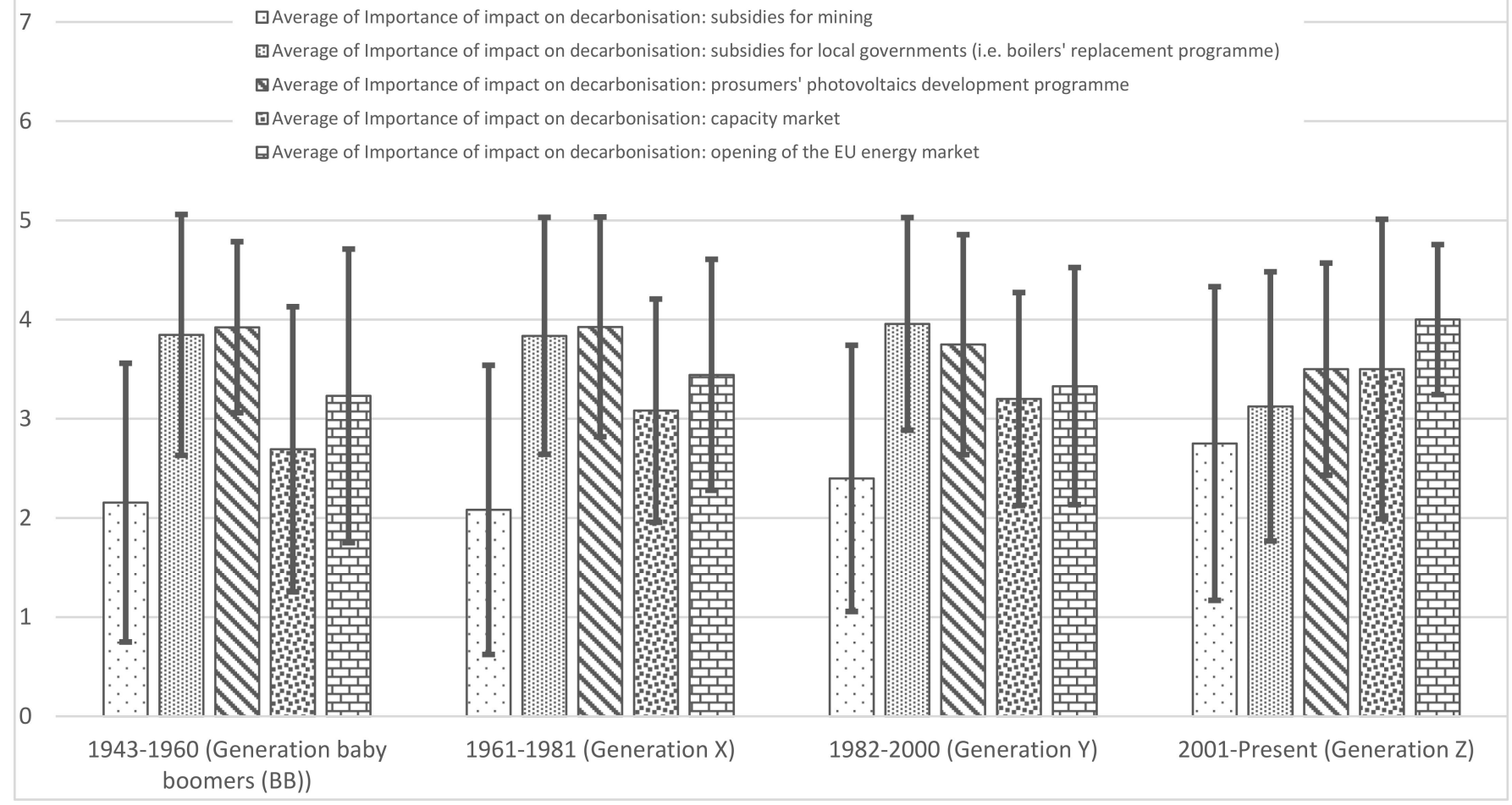

Figure 4. Average importance of impact on decarbonisation with marked standard deviations. Source: Own research based on the results of an online survey, $n=444$.

Figure 5 presents the distribution of the number of respondents depending on age and sex, with an additional indication of the place of residence. Generations X and Y are representative, so their results are taken into account in particular. 


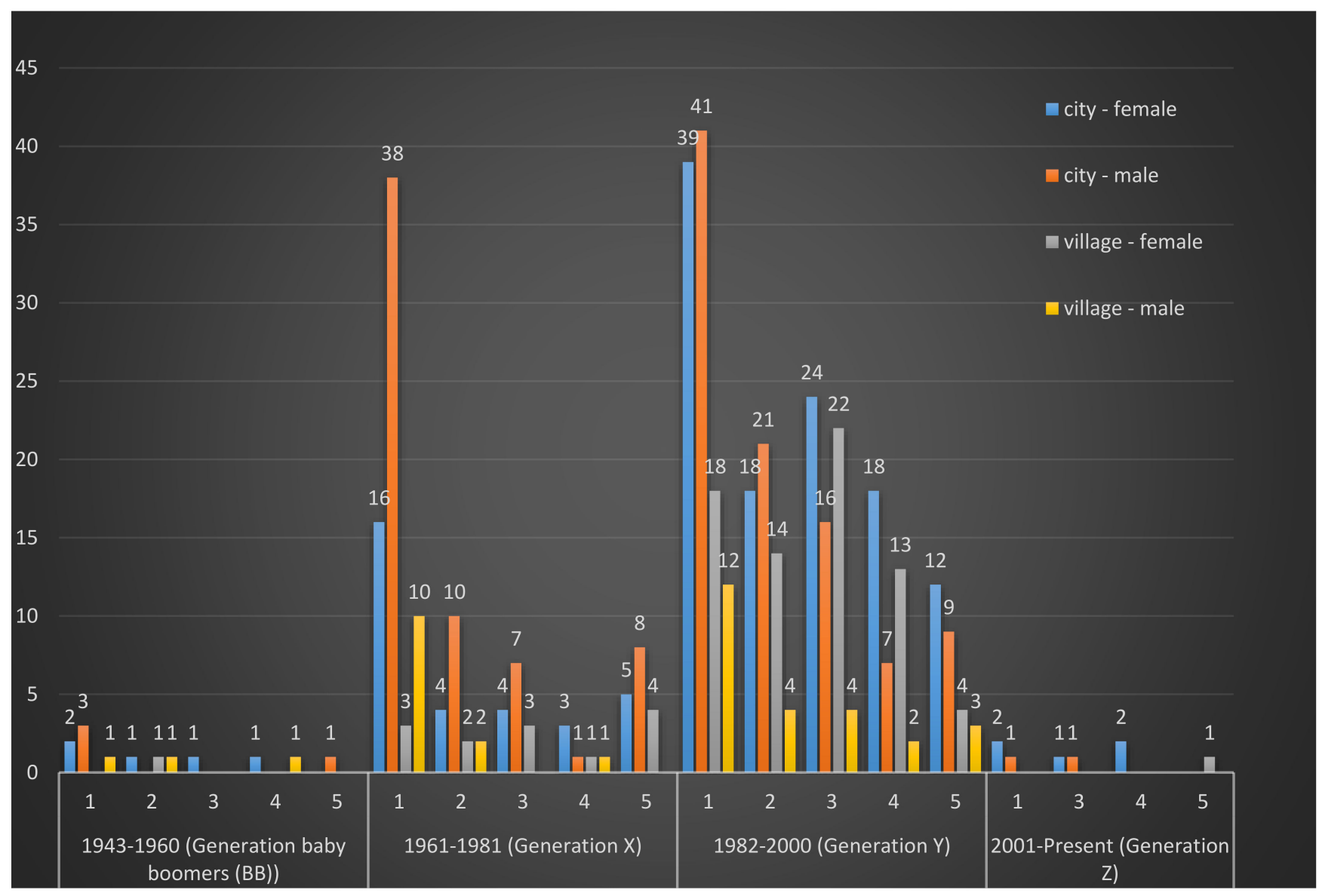

Figure 5. Distribution of responses by sex and localisation by age. Source: Own research based on the results of an online survey, $n=444$.

Figure 6 and Table 4 show the average levels of answers to the question about the necessity of transferring activities directly to local levels, and standard deviations. Generations $\mathrm{X}$ and $\mathrm{Y}$, which we consider due to them representing the majority of respondents, responded unanimously. For them, priority is given to local support programmes of furnace replacement and programmes related to photovoltaics.

Table 4. Mean values in responses to the question of necessity, scored from 1 to 5 ; sorted by age.

\begin{tabular}{cccccc}
\hline & \multicolumn{5}{c}{ Average of Necessity of Transferring Actions from the } \\
Central to the Local Level
\end{tabular}

Source: Own research. A-Subsidies for the residents/end users (i.e., boilers' replacement programme); BProsumers' photovoltaics development programme; C-Compensation for electricity, energy storage, production during the daytime, and consumption at night; D-Funds for environmental protection; E-Support of development of modern power sources (CHP bonus, renewable energy sources).

It is assumed that the standard deviation, being one-third of the mean, indicates a narrow distribution (Tables 5 and 6). 


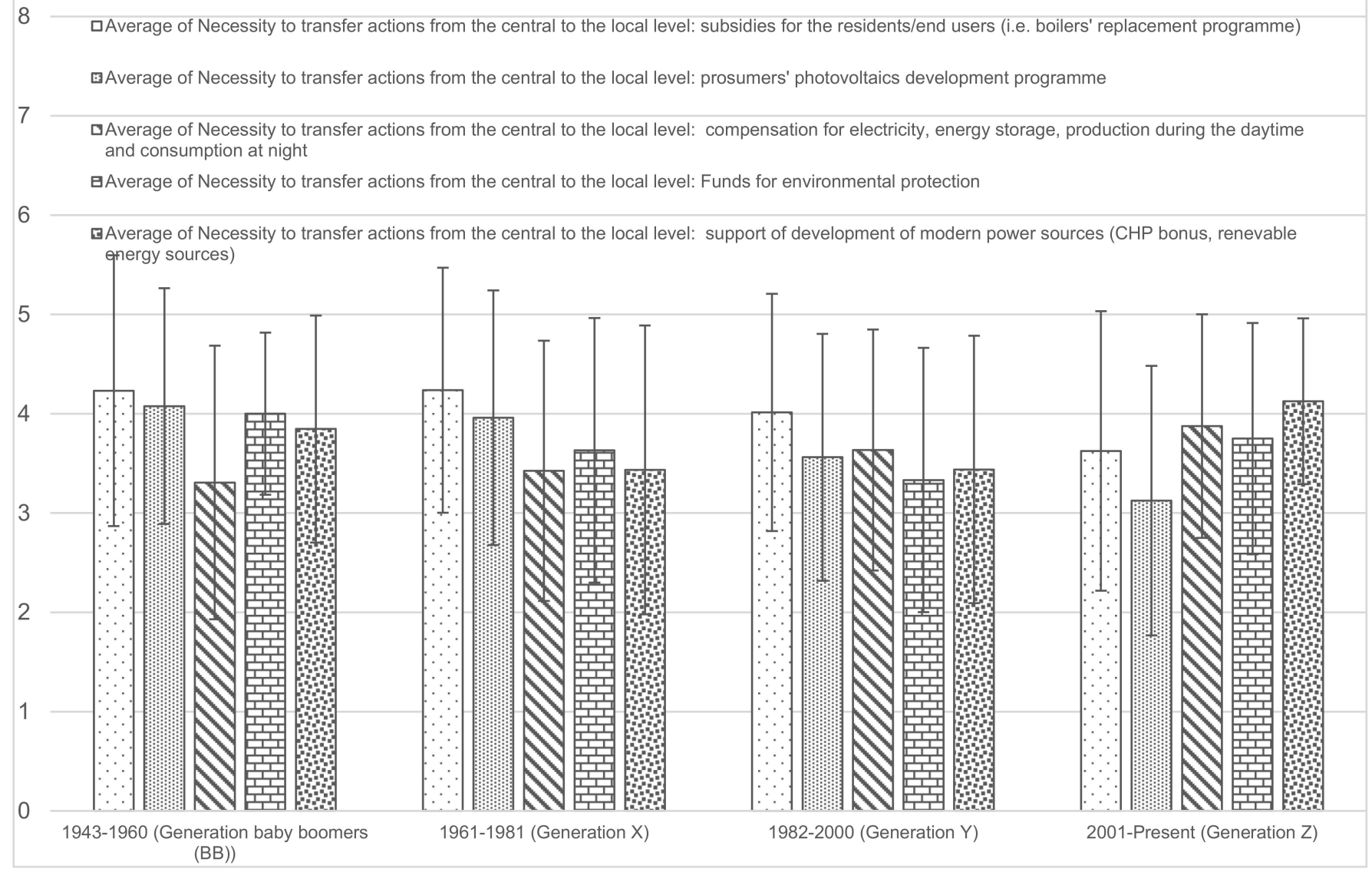

Figure 6. Average of necessity of transferring activities directly to local levels. Source: Own research based on the results of an online survey, $n=444$.

Table 5. Mean values in responses to the question of necessity, scored from 1 to 5; sorted by age, with marked standard deviations.

\begin{tabular}{cccccc}
\hline & i1 & i2 & i3 & i4 & i5 \\
\hline Average & 2.31 & 3.90 & 3.80 & 3.16 & 3.37 \\
Standard deviation & 1.38 & 1.12 & 1.11 & 1.11 & 1.19 \\
\hline Source: & &
\end{tabular}

Source: Own research. Notes: The answers to the first question were ranked in importance from 1 to 5 , and numbers provided from 1 to 5 for subsequent responses.

Table 6. Average values and standard deviation to the responses n1-n5.

\begin{tabular}{cccccc}
\hline & $\mathbf{n 1}$ & $\mathbf{n 2}$ & $\mathbf{n 3}$ & $\mathbf{n 4}$ & $\mathbf{n 5}$ \\
\hline Average & 4.07 & 3.68 & 3.57 & 3.44 & 3.46 \\
Standard deviation & 1.21 & 1.27 & 1.24 & 1.32 & 1.36 \\
\hline
\end{tabular}

Source: Own research. Notes: The answers to the second question were ranked in Necessity from 1 to 5 , and numbers provided from 1 to 5 for subsequent answers.

Table 7 summarises the obtained covariance levels for questions 1 and 2, respectively, for answers from i1 to i5 and from $\mathrm{n} 1$ to $\mathrm{n} 5$.

The highest covariance of 0.68 is for the answer to the question about photovoltaics and its support in questions 1 and 2 . This covariance confirms that the calculations are correct and that the data obtained from the study are accurate. 
Table 7. Covariances for the response set for i1-i5 through n1-n5.

\begin{tabular}{cccccc}
\hline Covariation & $\mathbf{n 1}$ & $\mathbf{n 2}$ & $\mathbf{n 3}$ & $\mathbf{n 4}$ & $\mathbf{n 5}$ \\
\hline i1 & 0.25 & 0.06 & 0.17 & 0.20 & 0.14 \\
i2 & 0.59 & 0.45 & 0.33 & 0.18 & 0.17 \\
i3 & 0.41 & 0.68 & 0.26 & 0.22 & 0.30 \\
i4 & 0.13 & 0.25 & 0.31 & 0.33 & 0.37 \\
i5 & 0.13 & 0.17 & 0.38 & 0.49 & 0.42 \\
\hline
\end{tabular}

Source: Own research.

The second-largest covariance (0.59) is for the answer to the question about the support of local government and the transfer of support to local areas from the central level, both in questions 1 and 2. This also confirms the correctness of the obtained data and the correctness of the answers provided. This covariance is graphically presented in Figure 7.

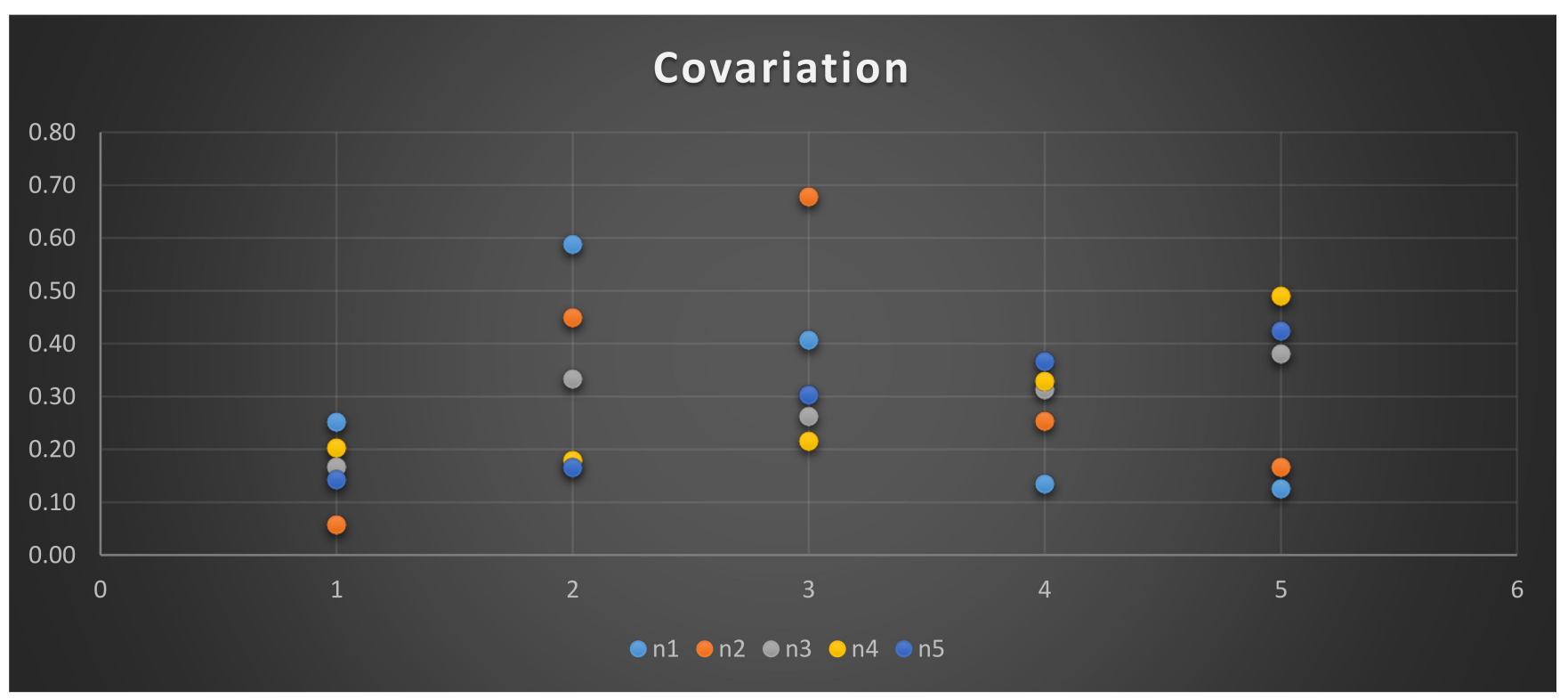

Figure 7. Covariation. Source: Own research based on the results of an online survey, $n=444$.

Both covariation and strong correlation can indicate a strong relationship where the result is above 0.5 . In the case of $i 3 n 2$, robust covariation is confirmed (0.68), and the correlation (0.49) is sufficiently strong (Figure 6). The results from the sample of 444 indicate that the strongest covariation and correlation concerns the importance of the impact on the decarbonisation of the prosumer solar photovoltaics development programme.

The correlation was also calculated, which confirmed the above conclusions for the covariance. The correlations are presented graphically in Figure 8.

Table 8 shows two correlation coefficients that are higher than the remaining ones. Correlation at the level of 0.43 in response to questions i2 and n1 suggests that the voters were in favour of entrusting the actions to local government rather than centralising them. They reasoned that the local authorities would know their residents better (Figure 8).

At the level of 0.49 , an even stronger correlation is visible in responses to questions i3 and $\mathrm{n} 2$. This correlation between answers to these two questions suggests that voters, who think that photovoltaics is a crucial factor in the decarbonisation process, would prefer local governments to distribute the subsidies instead of there being centrally controlled distribution of funds. These two coefficients suggest strong support for the local governments by the community (Figure 9). 


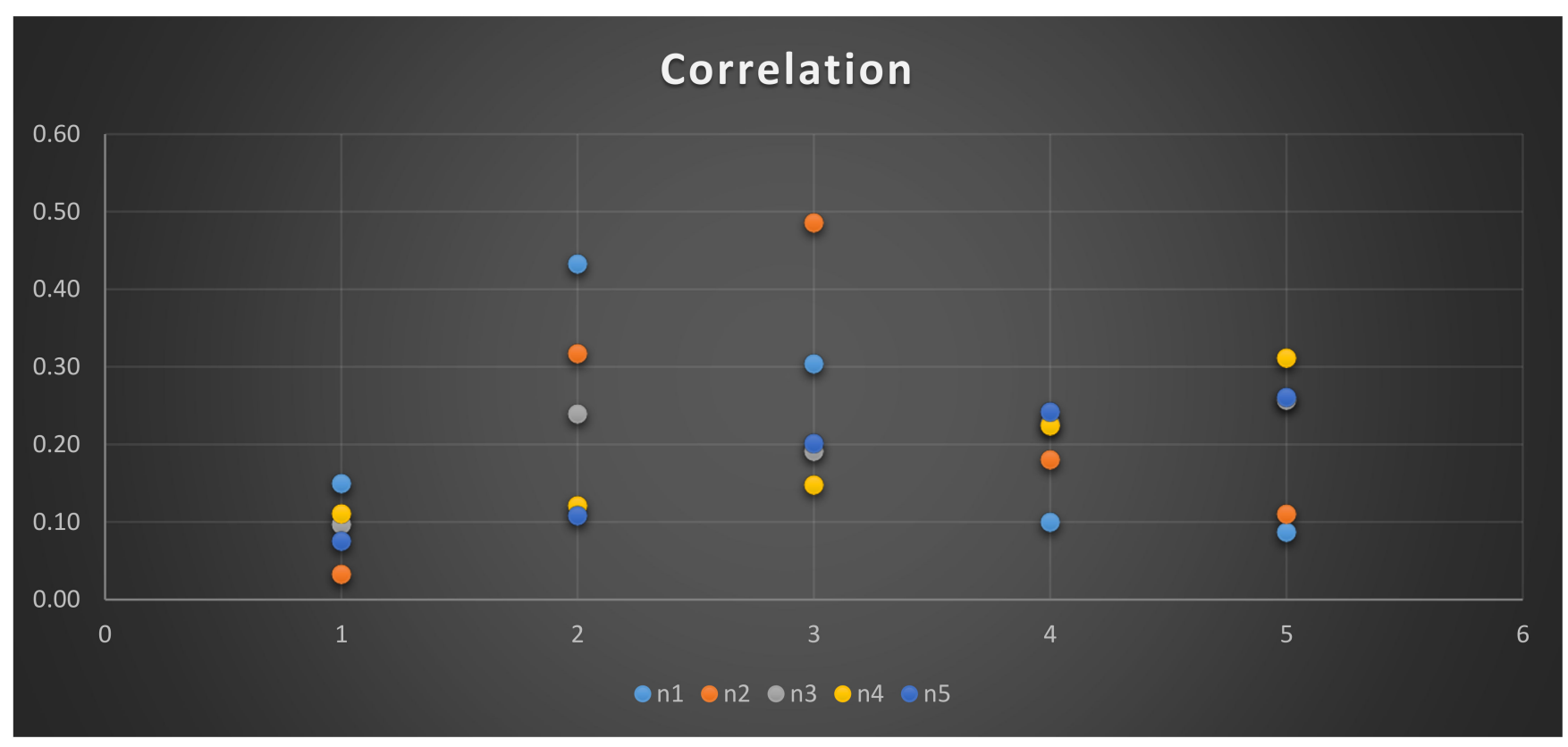

Figure 8. Covariation. Source: Own research based on the results of an online survey, $n=444$.

Table 8. Correlations for the response set for i1-i5 through n1-n5.

\begin{tabular}{cccccc}
\hline Correlation & $\mathbf{n 1}$ & $\mathbf{n 2}$ & $\mathbf{n 3}$ & $\mathbf{n 4}$ & $\mathbf{n 5}$ \\
\hline i1 & 0.15 & 0.03 & 0.10 & 0.11 & 0.08 \\
i2 & 0.43 & 0.32 & 0.24 & 0.12 & 0.11 \\
i3 & 0.30 & 0.49 & 0.19 & 0.15 & 0.20 \\
i4 & 0.10 & 0.18 & 0.23 & 0.22 & 0.24 \\
i5 & 0.09 & 0.11 & 0.26 & 0.31 & 0.26 \\
\hline
\end{tabular}

Source: Own research.

The next question was about the solutions that the EU should introduce in the field of decarbonisation. Respondents could give a free, subjective answer, or several answers, to this open-ended question. The aim was to obtain as many attitudes and opinions as possible to analyse the decarbonisation further. It should be emphasised that this phenomenon is still poorly understood in society. Of the respondents, only 238 answered this question; about $20 \%$ of the participants indicated that they had no opinion, could not judge, did not know, or found it hard to assess.

The respondents' answers to the question "What solutions do you think the EU should introduce for regulations regarding decarbonisation?" were categorised into four groups. It should be following sentence in the Table 9 common responses to the survey are shown.

In addition to the solutions mentioned above, other respondents suggested that there should be a standard energy policy and a uniform EU position toward natural gas suppliers. Survey participants also pointed out that no country in the EU without extensive financial and technical capabilities in hydroelectric power and geothermal energy had decarbonised its energy sector without a nuclear power plant.

Another proposal concerned a change in the law, namely, a new EU regulation defining a binding prospect for the coal industry's liquidation and establishing a special decommissioning fund for mining in the EU. According to the respondents, the problem of the existing EU solutions is the lack of appropriate bonuses (incentive bonuses) for countries ahead of schedule to reduce $\mathrm{CO}_{2}$ emissions. The European Commission should develop its own, independent, individual national schedules, based on its analyses in this study. 


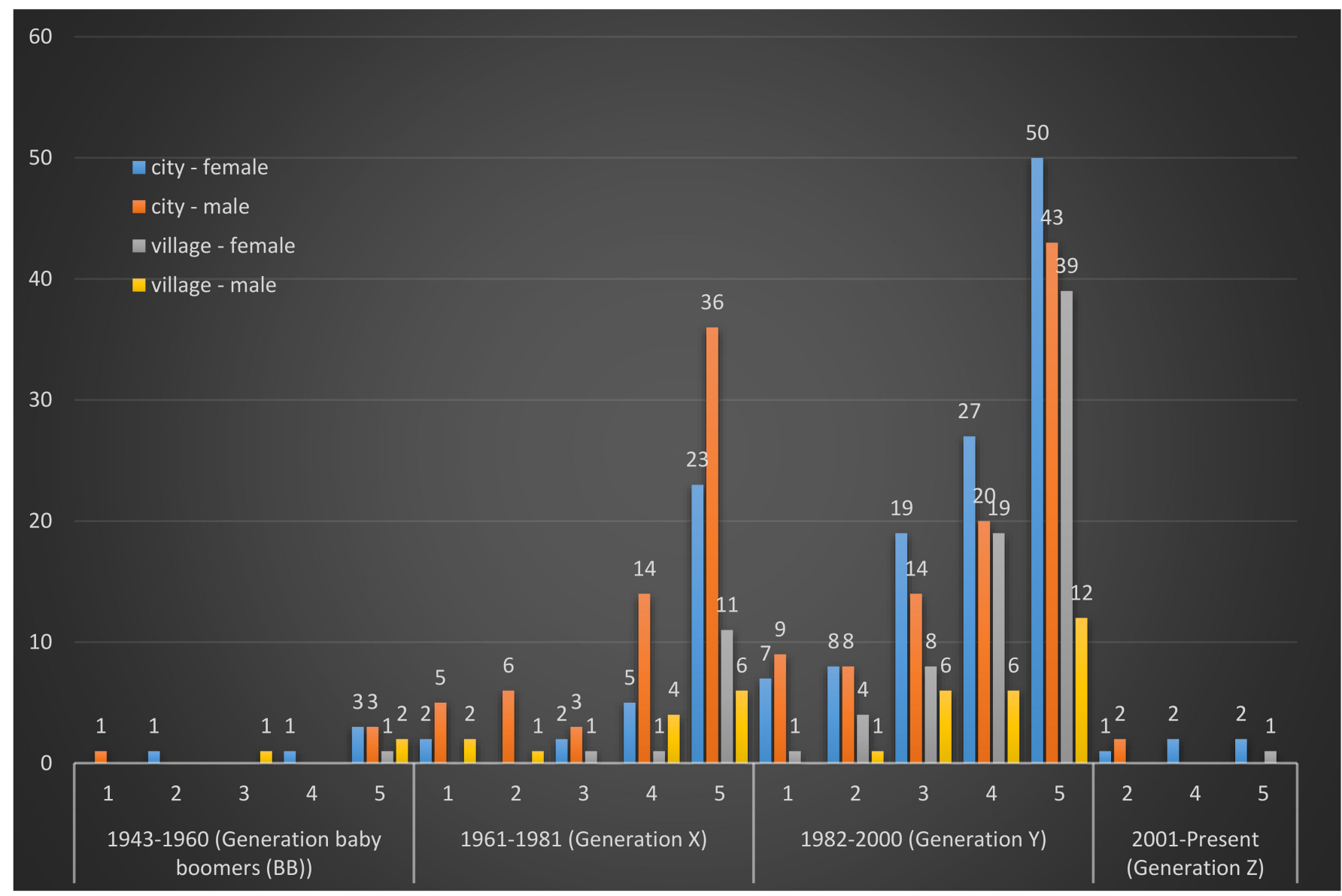

Figure 9. Distribution of responses by sex and localisation by age. Source: Own research based on the results of an online survey, $n=444$.

While analysing what regulations the EU should introduce in decarbonisation, a small group of respondents suggested that the energy market should not be controlled and should not receive subsidies, with energy policy left as a national policy under the control of each country. These respondents also stated that the largest EU countries were the ones that set the standards for decarbonisation.

Another respondent suggested transforming the energy sector toward large zeroemission sources, such as nuclear, offshore wind, or hydropower. However, another respondent indicated that Poland had a high degree of afforestation.

The respondents also highlighted the following issues:

- introduction of $\mathrm{CO}_{2}$ certificates;

- introduction of emission limits for households;

- mandatory end to solid fuel stoves (coal);

- $\quad$ increasing the awareness of society and consumers about the positive impact of renewable energy sources on the natural environment and human health;

- $\quad$ elimination of own contribution through EU subsidies;

- $\quad$ elimination of tedious procedures (minimising formalities) for replacing heating devices; and

- making member states accountable for the effects of decarbonisation.

In conclusion, although the results were based on the respondents' subjective opinions, individuals' views and attitudes within the external environment for decarbonisation are fundamental, especially when looking at the best way to reduce $\mathrm{CO}_{2}$ emissions. 
Table 9. EU solutions in the field of decarbonisation: Implementation possibility by individual member states, according to respondents.

\begin{tabular}{|c|c|c|}
\hline No. & Action & Characteristics and Specification \\
\hline 1 & Coal management & $\begin{array}{l}\text { - } \text { coal import ban } \\
\text { - high customs duties } \\
\text { - no smoking of coal } \\
\text { - } \text { the use of coal as fuel is prohibited } \\
\text { - } \text { reduction of coal extraction in mines } \\
\text { - } \text { a total ban on the production of energy from fossil fuels } \\
\text { - introduction of high penalties }\end{array}$ \\
\hline 2 & Grants & $\begin{array}{l}\text { - } \text { granted to households and entrepreneurs } \\
\text { - } \text { subsidies for prosumer solar farms- dedicated EU programmes } \\
\text { - } \text { reduction of subsidies to energy } \\
\text { - } \text { intensive industries } \\
\text { - } \text { for renewable energy sources } \\
\text { - } \quad \text { subsidies for households to replace old stoves } \\
\text { - }\end{array}$ \\
\hline 3 & Nuclear energy & $\begin{array}{l}\text { - common projects } \\
\text { - conduct/implement a low-emissions nuclear policy } \\
\text { - } \text { the example of France } \\
\text { - develop and promote nuclear energy } \\
\text { - } \quad \text { the EU should allow the construction of nuclear power plants from EU funds } \\
\text { - } \quad \text { recognition of nuclear energy as an effective decarbonisation mechanism }\end{array}$ \\
\hline 4 & RES technologies & $\begin{array}{l}\text { - } \text { support and assistance- legal and technical support } \\
\text { - } \text { penalties for the lack of RES investments } \\
\text { - } \text { subsidising small RES installations of various types } \\
\text { - } \text { growing the share of renewable power sources in total power production }\end{array}$ \\
\hline 5 & Taxes & $\begin{array}{l}\text { - } \mathrm{CO}_{2} \text { taxation, including the aviation industry } \\
\text { - impose charges and emission duties } \\
\text { - introduce a carbon footprint tax for products imported from outside the EU } \\
\text { - introduction of high carbon taxes, including for households }\end{array}$ \\
\hline
\end{tabular}

Source: Own research based on the results of an online survey, $n=238$.

Considering the results of the assessment of the main factors influencing the decarbonisation process in Poland, in which 249 respondents provided detailed answers, around 20\% of the survey participants did not give any answer, indicating that they had no response, did not know, or could not judge.

The responses to the questionnaire indicated that the main factors in the decarbonisation process, according to the respondents, were subsidies and nuclear energy (approximately $50 \%$ of the respondents mentioned nuclear points). Among the most frequent answers were replacing coal-fired energy plants with substitute like e.g., energy plants and the decommissioning of old solid fuel stoves. Considering that the respondents were asked an open-ended question and each had the opportunity to provide long answers, the most frequently indicated determinants affecting the elimination of $\mathrm{CO}_{2}$ emissions are presented in Figure 10.

Respondents seem to be aware that there is no single, simple solution to reducing fossil fuel consumption and $\mathrm{CO}_{2}$ emissions. Divesting from fossil fuels is a great challenge for Poland. The largest sources of $\mathrm{CO}_{2}$ emissions are the combustion of fossil fuels in power plants, transport (cars and planes), processes related to the production of industrial goods, and deforestation. Poland has to face these problems to transition to a low-carbon future [35-37]. 

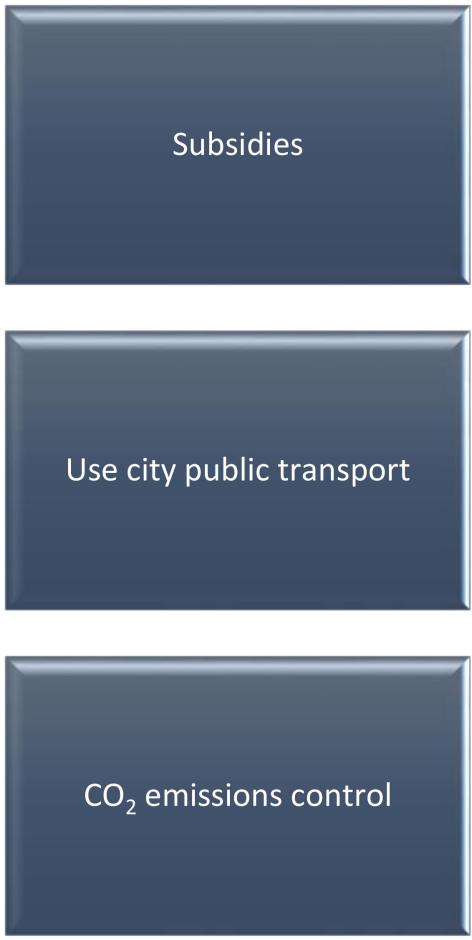
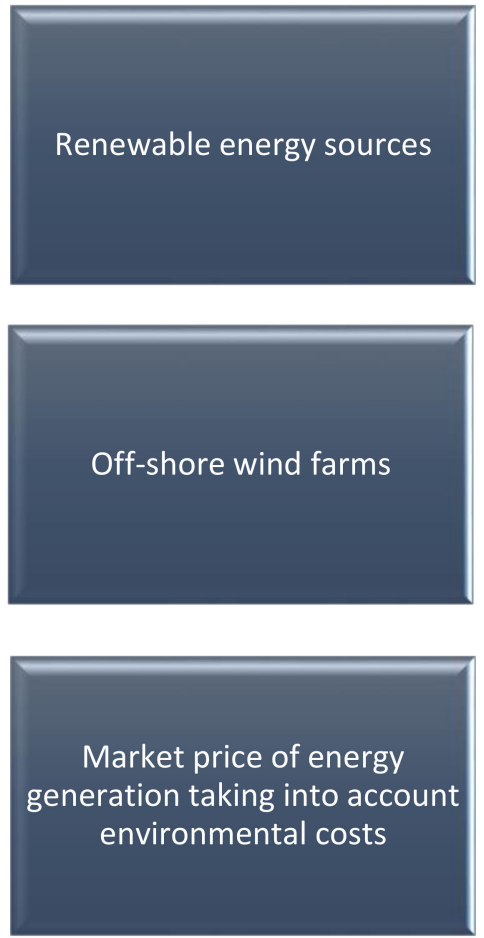
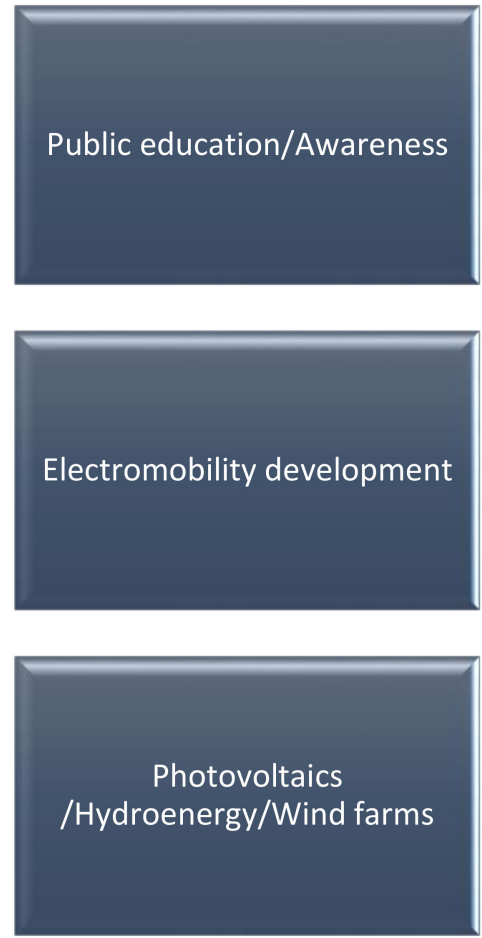

Figure 10. Main determinants of decarbonisation according to the respondents. Source: Own research based on the results of an online survey, $n=249$.

\section{Discussion and Conclusions}

The study's main aim was to reveal the determinants of decarbonisation influencing the energy transformation in Poland. Poland is one of the countries whose energy is still based on carbon (the others are China, Russia, Australia, Ukraine, and the USA). Currently, the politics of the whole world resists decarbonisation. In Poland's case, the coal share is decreasing, but it is still the most important fuel for electricity production. Governments must implement policies that are environmentally friendly, cost-effective, and socially acceptable. Social acceptance risk plays a significant role in Poland, so it is crucial to know the factors influencing decarbonisation and energy transformation. The authors conducted a survey, the results of which should be of benefit to policy-makers and researchers worldwide. In our opinion, it is novel research and has important results concerning energy and climate change. It also presents the directions enabling the diffusion of knowledge regarding decarbonisation to develop a sustainable energy strategy for Poland.

The authors investigated phenomena that have not been studied in the literature so far. The following determinants impact decarbonisation: subsidies for mining, subsidies for local governments (e.g., decommissioning of furnaces), prosumer solar photovoltaics development programmes, market capacity, and opening up the EU energy market. The authors were interested in social support for these determinants. Research has shown that mining subsidies had no impact on the decarbonisation process. The respondents stated that the development programmes for prosumer solar photovoltaics had a significant impact on eliminating $\mathrm{CO}_{2}$ emissions due to their harmfulness to the environment. Local governments provide better support for the decarbonisation process, and should support such activities. Poland was generally seen as a clean energy laggard, but it shot up the solar energy charts by adding $2.2 \mathrm{GW}$, more than double its capacity last year. Unleashing this potential is crucial for sustaining momentum in the EU solar sector and meeting European Green Deal climate and energy targets. To make the most of this golden opportunity, the rate of deployment for solar needs to increase exponentially, with innovative applications such as floating solar, agricultural photovoltaics, and building-integrated photovoltaics showing significant potential to foster further demand and growth. 
Now is not the time for complacency, but for action to ensure a green recovery from the pandemic and a just global transition towards a decarbonised and renewable future.

We suggest that the main pathways in the decarbonisation process in Poland could include the following:

- facilitating investments in wind, solar, geothermal, and hydroelectric energy;

- $\quad$ consciously improving energy policy and energy security;

- coordinating the development of the most effective types of RES;

- construction of a nuclear power plant;

- $\quad$ regulating energy prices and prices for products with high carbon content; and

- $\quad$ transformation of Silesia.

Based on the survey results, we can draw similar or even the same specific conclusions about the critical determinants of Poland's energy market transformation processeducation, knowledge, and awareness for both society and business. Other factors include the use of renewable energy, the construction of a nuclear power plant, subsidies for renewable energy sources, the replacement of furnaces, the development of new technologies, the inclusion of transmission infrastructure, and changes in people's deeply rooted beliefs. The study reviewed the international literature on the theory and practice of decarbonisation, emphasising the experiences of other countries, including the USA and China. The authors also rely on German and Scandinavian experiences. However, the carbon dioxide emissions resulting from burning coal are still a major problem in other countries. The USA and China were used as examples because they still use significant amounts of coal for energy production and locally for heat production. Germany has long been marginalizing this problem through programmes for the development of renewable resources. Scandinavia, on the other hand, does not use coal at all to produce energy and coal. The selection of the present comparisons at the current stages of the development of decarbonisation was deliberate. To reduce greenhouse gas emissions in Poland by 2050, the decarbonisation of the economy should occur four times faster than in recent years. In the years 2030-2050, our actions should double in intensity, and the social perceptions of this phenomenon are essential. For the environment, the replacement of coal by gas is of enormous importance. Gas is the next step to stop emissions completely. Gas burns exceptionally cleanly (even without exhaust gas treatment), emitting twice as much $\mathrm{CO}_{2}$ as the calorically equivalent amount of carbon. The energy conversion efficiency is high. Even small engine installations offer electrical efficiency comparable to the largest coal installations $(\sim 45 \%)$, and the ceiling of large gas-steam units $(\sim 60 \%)$ is unattainable for coal-fired power plants. Gas blocks are cheap in terms of investment, and are quick to build and flexible (quick start-up/shutdown). We can find an analogy with the analysis in Sadik-Zada and Gatto [38]. In order to account for the differences between advanced and developing/transition economies, we have included a dummy variable, which takes the value "1" for all developing and transition economies and the value " 0 " for advanced economies. This volatility reflects the partially differentiated influence of the energy sector on the rest of the economy in these two groups. There is a difference between developing/transition economies and advanced economies in terms of public debt levels.

This study concluded that several paths lead to decarbonisation and energy market transformation and, thus, to climate neutrality. These empirical results could be used to diagnose the state's level of use of instruments to implement its sustainable development goals. Such analytical research has not yet been presented for Poland; this study is the first to attempt to identify the determinants of the decarbonisation process in Poland. This study can be used as a basis for further research on this topic. When we compare natural gas with fuels such as coal and oil, it has a lower carbon intensity. The use of gas as a fuel therefore leads not to total elineation, but only to a reduction in carbon dioxide emissions. As widely known, this emission is mostly responsible for the anthropogenic changes in our global climate. Therefore, natural gas used as a fuel is considered only as a temporary source of energy on the way to the complete elimination of carbon dioxide emissions. This is particularly evident in energy mixes dominated by coal [39]. However, 
significant criticisms are being made against this view. One of the more famous researchers is Howarth's (2014) argues that both energy extracted from gases which are extracted from shale rocks is very harmful to the environment. According to this view, these sources have a greater impact on climate change than the burning of coal and oil. Only natural gas-based electricity generation has a moderate impact on the change in emissions. this varies from sector to sector of the economy. In the heating and mobility sector, for example, natural gas has a higher level of gas share, GHGs. Howarth argues, and gives this as the main argument that methane is particularly harmful. Natural gas has lower carbon dioxide emissions compared to shale gas. However, it is more harmful that it has a higher methane emission factor. According to his view, even small amounts of methane are more harmful to global warming than carbon dioxide emissions. Nevertheless, this argument is no longer important when we consider the development of energy technologies that significantly reduce methane emissions [38].

Additionally the Authors have to add in the case of no decarbonisation significant part of the existing energy infrastructure, regardless of climate change, will need to be renewed in the next 20 to 30 years. More than 50\% of the capacity of centrally dispatched generation units will most likely be decommissioned by 2035.1At the same time, more than three quarters of the aerial high- and medium voltage lines that form the basis of the transmission system are now over 25 years old.16 This reality provides an opportunity to design and build with a zero-carbon mindset instead of retrofitting or prematurely shutting down existing assets. In addition, Poland, with its large forest area, has a net carbon sink (capturing $34 \mathrm{MtCO} 2 \mathrm{e}$ in 2017)17 that the country could use to offset emissions from hard-to-abate economic activities such as agriculture [40].

Future research should concern confirmation of whether the Polish government deals with the decarbonisation process accordingly with social expectations. Moreover, a detailed study should be carried out as to whether the Polish government is willing to act on this matter. Poland's zero-carbon economy shift should be a long-term and stable plan ideally working by 2050. What is more, this should also be coherent with a medium-term reference aim for objectives and undergoing legislative changes. Are the Polish government and society willing to accept the sunset of the mining sector? What is more, are they accepting the actual need to decrease the conventional coal-fired power production in up to 30 years? How about accepting the urging need of pushing the debate on the electricity generation's future in Poland? It would be crucial to, before 2050, explore feasible methods to a near zero-carbon system which would deliver double the amount of energy as today? Research should also be provided in terms of the social acceptance of a low-carbon transition plan for the mining industry in Poland. It should also ensure a consistent regulatory framework taking into account inclusion of the global climate regulations issues in both foreign and export-oriented policies and also the early breakthrough procedures innovations distribution nationwide.

Author Contributions: Conceptualization, M.W.-J., M.C., and G.K.; Data curation, M.W.-J., M.C., G.K., and K.B.-R.; Formal analysis, M.C., G.K., and B.S.; Funding acquisition, M.W.-J., M.C., G.K., B.S., and K.B.-R.; Methodology, B.S. and K.B.-R.; Project administration, M.W.-J. and M.C.; Resources, M.W.-J. and M.C.; Software, G.K.; Supervision, M.W.-J. and M.C.; Validation, M.W.-J. and M.C; Visualization, M.W.-J., M.C., and B.S.; Writing—original draft, M.W.-J., M.C., G.K., B.S., and K.B.-R.; Writing-review and editing, M.W.-J. and M.C. All authors have read and agreed to the published version of the manuscript.

Funding: This project was financed within the framework of the programme of the Ministry of Science and Higher Education under the name "Regional Excellence Initiative" in the years 2019-2022; project number 001/RID/2018/19; the amount of financing was PLN 10,684,000.00. The publication was financed from the subsidy granted to the Cracow University of Economics (to M.W.-J.).

Institutional Review Board Statement: Not applicable.

Informed Consent Statement: Not applicable.

Data Availability Statement: Data is contained within the article or supplementary material. 
Conflicts of Interest: The authors declare no conflict of interest.

\section{References}

1. Kiuila, O. Decarbonisation perspectives for the Polish economy. Energy Policy 2018, 118, 69-76. [CrossRef]

2. Global Economic Prospects, June 2020; Global Economic Prospects; The World Bank: Washington, DC, USA, 2020; ISBN 978-1-4648-1553-9.

3. Zenghelis, D. Securing Decarbonisation and Growth. Natl. Inst. Econ. Rev. 2019, 250. [CrossRef]

4. Knobloch, F.; Pollitt, H.; Chewpreecha, U.; Daioglou, V.; Mercure, J.F. Simulating the Deep Decarbonisation of Residential Heating for Limiting Global Warming to $1.5^{\circ} \mathrm{C}$. Energy Effic. 2019, 12. [CrossRef]

5. Victoria, M.; Zhu, K.; Brown, T.; Andresen, G.B.; Greiner, M. Early Decarbonisation of the European Energy System Pays Off. SSRN Electron. J. 2020. [CrossRef]

6. Hübler, M.; Löschel, A. The EU Decarbonisation Roadmap 2050 What Way to Walk? Energy Policy 2013, 55, 190-207. [CrossRef]

7. Oyewunmi, T.; Crossley, P.; Talus, K.; Sourgens, F.; Jones, K.B.; Jervey, B.B.; Roche, M. Decarbonization and the Energy Industry: An Introduction to the Legal and Policy Issues. Tulane Public Law Research Paper No. 20-9. 2020. Available online: https: / / ssrn.com/abstract=3548837 (accessed on 1 February 2021). [CrossRef]

8. Ang, B.W.; Su, B. Carbon Emission Intensity in Electricity Production: A Global Analysis. Energy Policy 2016, 94. [CrossRef]

9. Blyth, W.; Bunn, D.; Chronopoulos, M.; Munoz, J.; Bunn, D.W. Systematic Analysis of the Evolution of Electricity and Carbon Markets under Deep Decarbonisation, Norwegian School of Economics. 2014, pp. 1-36. Available online: https://openaccess. nhh.no/nhh-xmlui/handle/11250/227052 (accessed on 1 February 2021).

10. Zimon, G. An Assessment of the Strategy of Working Capital Management in Polish Energy Companies. Int. J. Energy Econ. Policy 2019, 9. [CrossRef]

11. Åhman, M.; Nilsson, L.J.; Johansson, B. Global Climate Policy and Deep Decarbonization of Energy-Intensive Industries. Clim. Policy 2017, 17, 634-649. [CrossRef]

12. Cheema-Fox, A.; Laperla, B.R.; Serafeim, G.; Turkington, D.; Wang, H. Decarbonization Factors. Harvard Business School Working Paper, No. 20-037. September 2019. Available online: https:/ / www.hbs.edu/faculty /Pages /item.aspx?num=56840 (accessed on 1 February 2021).

13. Hildingsson, R.; Kronsell, A.; Khan, J. The Green State and Industrial Decarbonisation. Environ. Politics 2019, 28. [CrossRef]

14. Leal-Arcas, R. Towards Sustainability in Trade, Energy and Climate. Mod. Environ. Sci. Eng. 2020, 6, 1-30. [CrossRef]

15. Marx, C. Climate Change and Financial Sustainability: A Regulator's Perspective. ERA Forum 2020, 21, 171-175. [CrossRef]

16. Tsakalidis, A.; Gkoumas, K.; Pekár, F. Digital Transformation Supporting Transport Decarbonisation: Technological Developments in EU-Funded Research and Innovation. Sustainability 2020, 12, 3762. [CrossRef]

17. Saługa, P.W.; Grzesiak, P.; Kaminski, J. Valuation of Decision Flexibility and Strategic Value in Coal Gasification Projects with the Option-to-Switch between Different Outputs. Energies 2020, 13, 2826. [CrossRef]

18. Olszewski, R.; Pałka, P.; Wendland, A.; Kaminski, J. A Multi-Agent Social Gamification Model to Guide Sustainable Urban Photovoltaic Panels Installation Policies. Energies 2019, 14, 3019. [CrossRef]

19. Hadfield, P.; Cook, N. Financing the Low-Carbon City: Can Local Government Leverage Public Finance to Facilitate Equitable Decarbonisation? Urban Policy Res. 2019, 37. [CrossRef]

20. Spencer, T.; Pierfederici, R.; Sartor, O.; Berghmans, N.; Samadi, S.; Fischedick, M.; Knoop, K.; Pye, S.; Criqui, P.; Mathy, S. Tracking Sectoral Progress in the Deep Decarbonisation of Energy Systems in Europe. Energy Policy 2017, 110, 509-517. [CrossRef]

21. Barrett, J.; Cooper, T.; Hammond, G.P.; Pidgeon, N. Industrial Energy, Materials and Products: UK Decarbonisation Challenges and Opportunities. Appl. Therm. Eng. 2018, 136, 643-656. [CrossRef]

22. Gephart, R.P. What Is Qualitative Research and Why Is It Important? Acad. Manag. J. 2004, 47. [CrossRef]

23. Hoppe, T.; de Vries, G. Social Innovation and the Energy Transition. Sustainability 2018, 11, 141. [CrossRef]

24. Svensson, O.; Khan, J.; Hildingsson, R. Studying Industrial Decarbonisation: Developing an Interdisciplinary Understanding of the Conditions for Transformation in Energy-Intensive Natural Resource-Based Industry. Sustainability 2020, 12, 2129. [CrossRef]

25. Capros, P.; Tasios, N.; de Vita, A.; Mantzos, L.; Paroussos, L. Model-Based Analysis of Decarbonising the EU Economy in the Time Horizon to 2050. Energy Strategy Rev. 2012. [CrossRef]

26. Mullally, G.; Byrne, E. A Tale of Three Transitions: A Year in the Life of Electricity System Transformation Narratives in the Irish Media. Energy Sustain. Soc. 2015. [CrossRef]

27. Antadze, N.; Westley, F.R. Impact Metrics for Social Innovation: Barriers or Bridges to Radical Change? J. Soc. Entrep. 2012. [CrossRef]

28. Schmidt, S.; Weigt, H. Interdisciplinary Energy Research and Energy Consumption: What, Why, and How? Energy Res. Soc. Sci. 2015, 10, 206-219. [CrossRef]

29. de Leon Barido, D.P.; Avila, N.; Kammen, D.M. Exploring the Enabling Environments, Inherent Characteristics and Intrinsic Motivations Fostering Global Electricity Decarbonization. Energy Res. Soc. Sci. 2020, 61. [CrossRef]

30. Immink, H.; Louw, R.T.; Brent, A.C. Tracking Decarbonisation in the Mining Sector. J. Energy S. Afr. 2018, 29. [CrossRef]

31. Leal-Arcas, R. New Frontiers of International Economic Law: The Quest for Sustainable Development. Univ. Pa. J. Int. Law 2018, 40,83 . 
32. Kulovesi, K.; Oberthür, S. Assessing the EU's 2030 Climate and Energy Policy Framework: Incremental Change toward Radical Transformation? Rev. Eur. Comp. Int. Environ. Law 2020, 29. [CrossRef]

33. International Energy Agency (IEA). World Energy Outlook 2015; International Energy Agency: Paris, France, 2015.

34. International Energy Agency (IEA). World Energy Outlook 2018; International Energy Agency: Paris, France, 2018.

35. Szczepańska-Woszczyna, K. Strategy, corporate culture, structure and operational processes as the context for the innovativeness of an organization. Found. Manag. 2018, 10, 33-44. [CrossRef]

36. Saługa, P.W.; Szczepańska-Woszczyna, K.; Miśkiewicz, R.; Chłąd, M. Cost of Equity of Coal-Fired Power Generation Projects in Poland: Its Importance for the Management of Decision-Making Process. Energies 2020, 13, 4833. [CrossRef]

37. Kinelski, G. The main factors of successful project management in the aspect of energy enterprises' efficiency in the digital economy environment. Energy Policy J. 2020, 23, 5-20. [CrossRef]

38. Sadik-Zada, E.R.; Gatto, A. The Puzzle of Greenhouse Gas Footprints of Oil Abundance. Socio-Econ. Plan. Sci. 2020. [CrossRef]

39. Sadik-Zada, E.R. Distributional Bargaining and the Speed of Structural Change in the Petroleum Exporting Labor Surplus Economies. Eur. J. Dev. Res. 2020, 32, 51-98. [CrossRef]

40. Engel, H.; Purta, M.; Speelman, E.; Szarek, G.; van der Pluijm, P. Carbon-Neutral Poland 2050. Turning a Challenge into an Opportunity; McKinsey Company: Warsaw, Poland, 2020. Available online: https://www.mckinsey.com/pl/ \{ $\} / \mathrm{media} / \mathrm{mckinsey/}$ locations / europeandmiddleeast/polska.raporty/carbonneutralpoland2050/carbonneutralpoland_mckinseyreport.pdf (accessed on 1 February 2021). 